\title{
CONTEXTOS SOCIALIZADORES QUE INFLUYEN EN LA RECEPCIÓN TELEVISIVA INFANTIL
}

Carmen Marta Lazo: Universidad Complutense de Madrid (España)

\section{Influencia de los mensajes televisivos en la infancia}

Las opiniones acerca de la influencia que ejerce el medio televisivo en los niños son muy diversas y contrarias, dependiendo del grado de discernimiento, de la capacidad de elección y de la posible selección más o menos autónoma que se les otorga a los menores. Algunos autores hablan de "teledependencia" que se puede manifestar en signos de decadencia de la personalidad que atenúa el desarrollo de las potencias de inteligencia. En esta línea, los apocalípticos observan que la adición televisiva conduce a la pereza, a la inactividad y la negación de otras actividades complementarias. Desde la perspectiva contraria, otros autores, en clave integrista, advierten que la televisión no perjudica a la infancia, que todo son ventajas porque es un medio positivo para los niños y que éstos no deben ser protegidos de manera especial.

Sin embargo, podemos argüir que el proceso no es tan simple. No se trata de considerar como válidos ni los planteamientos tecnófobos ni los tecnófilos, porque todo dependerá de una serie compleja de muchas variables relativas tanto a la cantidad de tiempo que el niño pase delante de la pantalla, como de la calidad del consumo que realice, a lo que se añaden las mediaciones que reciba en la familia, la escuela, el grupo de pares o las que le ofrezca el propio medio televisivo a través de los contenidos vistos.

El proceso cognitivo y perceptivo en los niños depende de distintas variables del contexto en el que viven. En este sentido, Martín Serrano (1990), refiriéndose a los niños como receptores de televisión, afirma que "la información de los medios de comunicación masiva puede ser la misma, pero el uso de esa información, el valor que tiene para el niño en la elaboración de una imagen de la realidad, se explica por el sistema social, económico, familiar, laboral, escolar, vecinal, en el que el niño se desenvuelve, más que por los contenidos de comunicación". Sin embargo, algunos autores establecen algunas generalizaciones en el desarrollo evolutivo, según la edad. Según Eines y Mantovani (1980), es "a los cinco años, cuando el niño cumple con más atención las reglas resultantes del papel que ha asumido, debido a que conoce mejor la vida social de los adultos. Comienza a adquirir conciencia de la ficción y la realidad,... e insiste en hacer las cosas tal como se presentan en la realidad".

En los primeros años de la vida de una persona es cuando se forman los patrones culturales y sociales, remitiéndonos a los estudios constructivistas piagetianos. El

Recibido: 12/07/1999---Aceptado: 23/09/1999---Publicado: 05/12/1999 
desarrollo evolutivo de la personalidad desde la infancia no avala las características mecanicistas, nemoreactivas y fragmentadas que las teorías conductistas atribuyen a la percepción y al procesamiento humano de la recepción (Fuenzalida y Hermosilla, 1991).

Las peculiaridades de cada receptor son un factor importante de cara a descifrar el mensaje, así niños de la misma edad los perciben de maneras muy diversas: "unos la describen de un modo simple y objetivo; otros observan sus detalles y relaciones; otros se sienten afectados y expresan su opinión sentimental; algunos recuerdan; en otros despierta fantasía" (Vega Alonso, 1958). Una de las variables que influye en "los objetivos imaginativos del niño", según Younis (1988), es la "evolución intelectual".

\section{Principales agentes mediadores que repercuten en el consumo televisivo: familia y escuela}

Además del desarrollo evolutivo del propio sujeto, otra variable importante que afecta al consumo televisivo es el primer contexto de pertenencia para el niño: la familia. "Lo que es factible a los padres es la educación del telespectador para que utilice el televisor como una "importante, actualizada y motivadora" ventana al mundo, como consecuencia hay que potenciar el diálogo familiar e interiorizar los temas presentados por la televisión" (Fuenzalida y Hermosilla, 1991).

Tradicionalmente, la familia ha constituido el primer agente socializador ya que tanto desde la perspectiva psicobiológica natural como social es el primer núcleo en el que se satisfacen las primeras necesidades del ser humano e influye sustancialmente en la configuración de la personalidad, los hábitos y las costumbres del sujeto infantil. Sin embargo, debido a la tecnificación de la sociedad se produce una demanda de calidad y profundidad en la formación desde las primeras edades, para satisfacer las necesidades educativas que el avance de la estructura social conlleva, obligando a las instancias educativas a hacerse cargo de esa función. Como afirma Jesús Palacios: "Padres, centros, instituciones y sociedad en general, han de afrontar un nuevo planteamiento en el que el niño sea sujeto y vértice de toda acción educativa...diseñando un modelo de educación que responda a los avances que la psicología evolutiva está aportando sobre el proceso de maduración en la primera infancia" (Berea, 1992).

Por otra parte, el nacimiento de la sociedad de la información, propiciado por los avances técnicos, hace que los medios de comunicación, en especial la televisión, se hayan convertido en un nuevo agente socializador con el que los niños pasan la mayor parte de su tiempo. Sin embargo, "la programación televisiva destinada al público infantil no responde, en la actualidad, a los criterios mínimos de calidad que la legislación española y la Directiva Europea establecen desde 1989 al respecto y que a menudo son olvidados en pro de exigencias económicas y comerciales" (Marta Lazo y De Ángel García, 1997). 
Por el citado motivo es fundamental que los más pequeños sean educados para poder comprender, interpretar y criticar de manera autónoma y activa los mensajes que reciben, y esta función corresponde a los otros dos agentes, primordialmente al sistema educativo. "La pedagogía moderna nos plantea como uno de sus objetivos el lograr individuos que sean capaces de interrogarse durante toda su vida y de encontrar las respuestas que transformen la realidad..." (Eines y Mantovani, 1980). Por lo que en este artículo analizamos de qué manera la familia y la escuela responden a esta competencia. En primer lugar, nos referimos a cómo se ajusta la Ley de Ordenación del Sistema Educativo (LOGSE) a este fin.

Ya que es el currículo la fuente documental en la que se reflejan los principios esenciales de la actual propuesta educativa, en los diferentes niveles de concreción (Diseño Curricular Base, Proyecto Curricular de Centro y Programaciones de Aula), estudiaremos el diseño curricular con el fin de analizar la importancia que se le da a los medios de comunicación en los distintos elementos que lo componen: objetivos generales de etapa, áreas curriculares, objetivos generales de cada área, contenidos y criterios de evaluación.

El currículo escolar de las etapas de escolarización de segundo ciclo de Enseñanza Infantil, niños de 4 a 6 años, y primer curso de Primaria, niños de 7 años, tiene como objetivos básicos la función compensatoria e integradora, debido a la generalización de la educación a toda la población, y la función de socialización para favorecer la cooperación grupal, la toma de iniciativas, el diálogo y el espíritu crítico por medio de las relaciones comunicativas de aula. Así mismo, se pretende desarrollar la individualización con el fin de que el alumno sea cada vez más autónomo, creativo y crítico para comprender y explicar, con creciente complejidad el mundo que le rodea. Desde estos parámetros y funciones se enmarcaría la enseñanza-aprendizaje de los medios de comunicación como fuentes de conocimiento de la realidad circundante y exterior, imágenes de una realidad que los alumnos deben ser capaces de observar, comprender e interpretar desde una perspectiva crítica y autónoma.

La LOGSE basa los principios psicopedagógicos del diseño curricular en una concepción constructivista de la enseñanza-aprendizaje. Esta concepción parte de la consideración de que los alumnos construyan aprendizajes significativos frente a repetitivos, estableciéndose una relación entre lo que ya saben y lo que se desea que aprendan; y que lo que aprendan sea funcional, útil para su vida diaria. Otra de las premisas es la importancia del nivel de desarrollo del alumno, ya que existen "diferentes períodos evolutivos con características cualitativamente diferentes entre sí y que están en la base de las posibilidades de razonamiento y aprendizaje".

La concepción del sujeto infantil ha cambiado en los últimos años, desde la psicopedagogía se ha demostrado que ya antes de los seis años "actúa, piensa, siente y se relaciona; no es un ser humano situado al margen de la realidad, sino un 
sujeto que interpreta y elabora desde una óptica propia su noción del mundo", de lo que se deriva la importancia de la educación desde las primeras edades, como un proceso interactivo donde el niño crece en función de unos parámetros tanto individuales como socio-culturales. Se configura, pues, como un ser "inteligentepensante, pues la inteligencia en el niño nace siendo acción, cada vez más intencionada, que se organiza en esquemas sensorio-motrices y que encuentra en la manipulación de elementos concretos un dominio de expresión privilegiado", "constructor-autor de su obra, capaz de producir una transformación sobre diversas materias y objetos, de participar en la resolución de problemas cotidianos mediante el gesto y la utilización de instrumentos y herramientas que le proporciona el medio que le rodea", "poseedor de lenguaje, capaz de representar, evocar y comunicarse con los que convive, actuar sobre el mundo exterior orientando su acción, liberar y organizar sus sentimientos propios, preguntar, responder, ordenar y dialogar", "en conquista de autonomía, otorgando sentido a sus acciones y elaborando hipótesis que le ayuden a interpretar el medio" y "con una estructura bio-psico-social en desarrollo, resultado de la interacción dialéctica entre el sujeto y el medio. En esta interacción el sujeto no es pasivo, receptivo, sino que ejerce el papel activo en la construcción de su medio y de su propio crecimiento por medio del diálogo y aprendizaje que establece con la acción y la palabra" (DCB Enseñanza Infantil).

Establezcamos una diferenciación entre los elementos del DCB de Enseñanza Infantil y de Enseñanza Primaria, con el fin de definir las orientaciones generales y concretar la importancia y los enfoques que en cada una de estas etapas formativas se le da a los medios de comunicación.

\section{El currículo escolar de educación infantil}

En la franja de 4 a 7 años de edad, en el segundo ciclo de la Educación Infantil es cuando comienzan a "afirmarse los instrumentos cognoscitivos que permiten al niño conocer, organizar y comprender los objetivos por la función que cumplen según las acciones que se lleven a cabo. En la organización de la realidad, el niño consigue una mayor coherencia, ya que los objetos conservan su cualidad a pesar del tiempo y de las transformaciones (identidad cualitativa) y consigue comprender que una propiedad sucede a otra o se relaciona (funciones constituyentes)" (DCB Educación Infantil).

Atendiendo a la concreción del nivel de desarrollo en estas edades, desde la Educación Infantil se pretende "potenciar y favorecer el razonamiento, lo que implica una didáctica que sistemáticamente sitúe a los niños delante de los problemas cotidianos y escolares y los desafíen a buscar por ellos mismos, y con la ayuda orientadora del educador, las posibles soluciones. E implica, también una didáctica que admita opiniones, creencias, hipótesis, concepciones, que surgen desde la espontaneidad del razonamiento infantil". (DCB Educación Infantil). 
Los objetivos generales de la Educación Infantil se elaboran a partir de dos ejes fundamentales. Por un lado, "los requerimientos de la propia persona, como ser activo, procesador de información y capaz de autoconstruirse con el medio", atendiendo a su desarrollo integral evolutivo y madurativo, y por otro, las finalidades sociales, es decir, las aspiraciones consideradas valiosas en una comunidad, en el macrocontexto. Con el propósito de que la acción educativa sea de carácter global, teniendo en cuenta el estado evolutivo del sujeto y el medio en el que se desarrolla. A partir de estos núcleos surgen como finalidades básicas, presentes en el DCB formulado por el MEC:

- Desarrollo integral de la personalidad, en los ámbitos motor, cognitivo y afectivo.

- Desarrollo social, cooperativo, solidario y de respeto hacia los demás.

- Equilibrio afectivo y seguridad básica.

- Independencia, autonomía y espíritu crítico.

- Respecto a la singularidad y diversidad.

- Fomento de actitudes científicas.

- Desarrollo de la creatividad.

- Aspiración al logro de la paz.

Conseguir que los niños sean individuos independientes, autónomos, críticos y creativos repercutirá en el proceso de percepción activa y organizadora, "capaz de elaborar sus propias configuraciones" (Piaget, 1969) de los productos televisivos y de otros medios de comunicación.

Las áreas curriculares en la Educación Infantil, alrededor de las que se organizan los contenidos de los procesos de enseñanza-aprendizaje que globalizan los conceptos, procedimientos y actitudes, son: "Identidad y autonomía personal", "Conocimiento del medio físico y social” y "Comunicación y Representación".

* El área de "Identidad y autonomía personal" incluye el conocimiento del cuerpo, el dominio psicomotor y el desarrollo afectivo y socialización, esta última subárea se relaciona con la enseñanza de la potenciación de la toma de decisiones y del proceso socializador como inserción progresiva y crítica del individuo a la comunidad, objetivos que indirectamente repercutirían en la enseñanza de los medios de comunicación, al estar integrados en el seno de la sociedad, y en el aprendizaje de la capacidad de autonomía y crítica, determinado por el conocimiento de sus posibilidades perceptivas y motrices . 
* El área de "Conocimiento del medio físico y social", en su apartado del entorno social que tiene como fin la comprensión de la realidad social y cultural, también supondría un acercamiento a los medios de comunicación, que junto con los medios de transporte son un contenido autónomo dentro de una unidad didáctica.

*El área de "Comunicación y representación" es la que tiene subáreas más amplias y diversas: comunicación lingüística, desarrollo lógico y representación matemática, expresión plástica, expresión musical, y expresión corporal y dramatización. En ninguna se hace una mención específica a los medios de comunicación, recogiendo componentes apartados como son: el lenguaje, el sonido o la imagen, que juntos integran el sistema audio-visual.

En lo referente a los contenidos de cada una de las áreas y atendiendo al enfoque descriptivo desde el que se conciben los contenidos, realizando un análisis formal sin adentrarse en una valoración crítica, veamos cuáles están relacionados, directa 0 indirectamente, con los medios de comunicación.

El área de "Identidad y autonomía personal" responde a la necesidad de que "los pequeños conozcan global y segmentariamente su cuerpo, sus posibilidades perceptivas y motrices; deben poder identificar las sensaciones interoceptivas y externoceptivas que experimentan y servirse de las posibilidades expresivas del cuerpo para manifestarlas" (DCB Educación Infantil), aspecto que está relacionado con la percepción de los mensajes audio-visuales. En este sentido, en el apartado de contenidos de la unidad "Sensaciones y percepciones", dentro de la subárea "EI niño y su cuerpo", se incluyen todos los sentidos, entre ellos: el de la vista ("Luz y oscuridad; brillo; color; tono; forma; tamaño; memoria visual") y el del oído ("Ruido y silencio; intensidad de los sonidos; discriminación auditiva"), desembocando como uno de los objetivos generales en: "Conocer las características de los objetos utilizando las posibilidades sensitivas del cuerpo". Por otra parte, se incluye, en la subárea "Desarrollo afectivo y socialización" en la unidad "Autocontrol", como contenido actitudinal: "Iniciativa y autonomía en las tareas diarias, en los juegos y en la resolución de los pequeños problemas cotidianos", lo que integraría como una de las decisiones la selección de mensajes de los medios de comunicación. Y en la unidad "Socialización" se presenta como uno de los contenidos procedimentales: "Aplicación de las reglas fundamentales del diálogo: hábito de la escucha, interpretación del mensaje y expresión correcta de la respuesta", que parte del proceso de comunicación interpersonal para llegar en la siguiente área curricular: "Medio físico y social" al aprendizaje de la utilización de los medios de comunicación "general".

En la mencionada área se introduce a los escolares en el conocimiento de las funciones de los diferentes agentes sociales, partiendo de lo que les es más cercano, su familia y el colegio, hasta llegar a los medios de transporte y 
comunicación. En esta unidad es donde se recoge como materia autónoma la enseñanza del tema que centra nuestra investigación: los medios de comunicación. Los contenidos que abarca esta unidad son meramente descriptivos:

- Forma de comunicación: palabra, gesto y dibujo.

- Utilidad de los medios de comunicación.

- Tipos de medios: - comunicación personal: teléfono y correo.

- comunicación general: radio, televisión y prensa.

En la división de los contenidos, se establece dentro de los conceptuales: "La función social de los medios de comunicación", en los procedimentales: "Observación y atención a las manifestaciones, sucesos y acontecimientos que se relatan a través de los medios de comunicación" y en los actitudinales: "Interés por conocer los distintos medios de comunicación y sus funciones".

En cuanto a los objetivos que se persiguen mediante la enseñanza-aprendizaje de dichos contenidos se aprecia cierto enfoque más crítico: "utilizar adecuadamente, lograr una comprensión, tomar conciencia, valorar..." son algunas de las fórmulas expresivas que se utilizan:

- Descubrir y utilizar adecuadamente los medios de comunicación de fácil acceso a los niños.

- Lograr una comprensión adecuada de la función de los distintos medios de comunicación.

- Tomar conciencia de las distintas formas de comunicación entre los seres humanos y los agentes comunicadores.

- Valorar la importancia de los medios de comunicación en el intercambio de mensajes entre las personas.

Por último, la conceptuación del área de "Comunicación y representación" parte de la finalidad de "fomentar en los niños su vertiente de espectadores y asimiladores de manifestaciones culturales, pero sobre todo su papel de productores activos y originales" (DCB Educación Infantil). La primera subárea "Comunicación lingüística" es el canal en el que se integra y articula una serie de actividades para favorecer el logro de la competencia comunicativa, lo que se desprende de los objetivos generales: "Comprender, reproducir y recrear algunos textos de tradición cultural, mostrando actitudes de valoración, disfrute e interés hacia ellos", "Interesarse por el lenguaje escrito y valorarlo como medio de información y comunicación...", "Leer, interpretar y producir imágenes como una forma de comunicación y disfrute, identificando los elementos básicos de su lenguaje",... En la unidad "Sensibilización al sonido y desarrollo de la percepción auditiva" se incluye como contenido 
actitudinal: "Actitudes de escucha y apertura hacia los mensajes recibidos", lo que supone un criterio importante desde el punto de vista observacional. En lo referente a "La discriminación visual y organización espacio-temporal", título de otra unidad, se incluyen contenidos relacionados directamente con la enseñanza de los medios de comunicación escritos. Así en el apartado de los conceptos se incorporan: "Formas de comunicación gráfica: la imagen, la letra escrita", "Los elementos de la imagen gráfica: forma, color, tamaño, relación figura-fondo", "La lengua escrita como medio de comunicación e información", "Los instrumentos de la lengua escrita: libros, revistas, periódicos, carteles, anuncios,..." y "La organización espacial y temporal de los mensajes gráficos". En los procedimientos: "Interpretación de imágenes, carteles, grabados, fotografías, etc., que acompañan a textos escritos, estableciendo relaciones entre ambos", "Comprensión y producción de imágenes debidamente secuenciadas (ordenación cronológica de fotografías, historietas gráficas, en soporte magnético, etc.)" y "Percepción de diferencias y semejanzas ante imágenes y palabras escritas". $\mathrm{Y}$, dentro de los contenidos actitudinales, se persigue la "Valoración de la utilidad del lenguaje gráfico y de los textos escritos como medio de comunicación, información y disfrute". Con todos estos contenidos, los objetivos que se pretenden conseguir son:

- Desarrollar la discriminación visual de formas, tamaños y colores.

- Desarrollar la constancia perceptiva-visual.

- Desarrollar la percepción figura-fondo.

- Desarrollar la orientación espacial (la percepción de posiciones y relaciones espaciales y la orientación en el espacio gráfico.

- Desarrollar la organización temporal (nociones básicas de duración, cadencia, velocidad).

Por lo que respecta a los medios de comunicación, en las tres áreas y en diferentes bloques de contenidos, se utilizan como recurso didáctico, bien para visionar imágenes relacionadas con la unidad, por ejemplo en el área de "Medio Físico y Social, en la unidad de los animales" o para grabar el desarrollo de alguna actividad, por ejemplo, una dramatización, con el objeto de verla y evaluarla, entre todos, posteriormente.

\section{Los medios de comunicación en el currículo escolar de educación primaria}

"Enumerar una serie de rasgos que hagan referencia al desarrollo cognoscitivo de las niñas y los niños de la etapa de Educación Primaria es complejo dado que en la caracterización psicológica confluye siempre una serie de factores como la educación, las condiciones socio-culturales o la herencia, que matizarán sin duda 
estas características. No obstante, partiendo de que las fases del desarrollo no son estáticas se puede afirmar que existen una serie de rasgos comunes a la mayoría de las personas en un mismo 'estadio' evolutivo" (DCB Educación Primaria).

En los primeros años de la etapa de Educación Primaria, se "observa un notable progreso en la representación verbal, en el razonamiento y en la comprensión. Se sustituye paulatinamente la intuición por el razonamiento que al hacerse más analítico y objetivo, permite estructurar mejor la realidad... La necesidad de organizar sus conocimientos, de estructurarlos, de contrastarlos con información variada, lleva a los alumnos de estas edades a dar explicaciones y a prever resultados de un modo cada vez más racional y causal y menos finalista" (DBC Educación Primaria).

A lo largo de esta etapa se pretende que los alumnos amplíen sus capacidades de percepción de objetos y acontecimientos y desarrollen hábitos de observación, reflexión y búsqueda de soluciones, con la finalidad de "responder a las demandas de la sociedad y la cultura de nuestro tiempo" (Real Decreto 1006/1991 de Enseñanzas Mínimas de Educación Primaria). Entre los objetivos generales que se persigue que alcancen los alumnos de esta edad también aparece, como ocurría en Educación Infantil, el desarrollo de su autonomía: "Actuar con autonomía en las actividades habituales y en las relaciones de grupo, desarrollando las posibilidades de tomar iniciativas y de establecer relaciones afectivas" (R.D. 1006/1991). Asimismo, se le da importancia a la producción de mensajes por medio de los diferentes sistemas y códigos expresivos: "Comunicarse a través de los medios de expresión verbal, corporal, visual, plástica, musical y matemática, desarrollando el razonamiento lógico, verbal y matemático, así como la sensibilidad estética, la creatividad y la capacidad para disfrutar de las obras y manifestaciones artísticas".

Otros objetivos generales, que también deberían de tener en cuenta los programadores a la hora de diseñar los contenidos televisivos para fomentar los valores sociales y morales que desde el sistema educativo se propugnan, con el fin de aunar criterios para lograr unos mismos objetivos como son los siguientes:

- Establecer relaciones equilibradas y constructivas con las personas en situaciones sociales conocidas, comportarse de manera solidaria, reconociendo y valorando críticamente las diferencias de tipo social y rechazando cualquier discriminación basada en diferencias de sexo, clase social, creencias, raza y otras características individuales y sociales.

- Apreciar la importancia de los valores básicos que rigen la vida y la convivencia humana y obrar de acuerdo con ellos.

- Comprender y establecer relaciones entre hechos y fenómenos del entorno natural y social, y contribuir activamente, en lo posible, a la defensa, conservación y mejora del medio ambiente. 
- Conocer el patrimonio cultural, participar en su conservación y mejora y respetar la diversidad lingüística y cultural como derecho de los pueblos e individuos, desarrollando una actitud de interés y respeto hacia el ejercicio de este derecho.

- Conocer y apreciar el propio cuerpo y contribuir a su desarrollo, adoptando hábitos de salud y bienestar y valorando las repercusiones de determinadas conductas sobre la salud y la calidad de vida.

Las áreas de conocimiento en Primaria son más concretas que en Educación Infantil, que representan, como ya hemos visto, una configuración de contenidos agrupados de forma más general. En la etapa infantil los bloques temáticos se integran dentro de: "Lengua castellana y literatura"; "Lenguas extranjeras (inglés)"; "Matemáticas"; "Medio natural, social y cultural" y "Educación Artística (música y plástica)".

Si bien en el área de "Lengua castellana y Literatura" no se hace mención explícita a la enseñanza de los medios de comunicación, dentro de los objetivos, por extensión a los mensajes producidos por estos se haría referencia: "Comprender discursos orales y escritos, interpretándolos con una actitud crítica y aplicar la comprensión de los mismos a nuevas situaciones de aprendizaje". En el mismo sentido en el área de "Medio natural, social y cultural" se recoge como objetivo: "Identificar, plantearse y resolver interrogantes y problemas relacionados con elementos significativos de su entorno, utilizando estrategias, progresivamente más sistemáticas y complejas, de búsqueda, almacenamiento y tratamiento de información, de formulación de conjeturas, de puesta a prueba de las mismas y de exploración de soluciones alternativas", además aparece aquí la importancia instrumental de los avances tecnológicos: "Identificar objetos y recursos tecnológicos en el medio y valorar su contribución a satisfacer determinadas necesidades humanas, adoptando posiciones favorables a que el desarrollo tecnológico se oriente hacia usos pacíficos y de mayor calidad de vida".

Es en el área de "Educación Artística" en la que se evidencia y delimita un enfoque más descriptivo de los medios de comunicación audiovisuales y se detallan los elementos expresivos con la utilidad de que los alumnos sean también productores de mensajes:

- "Comprender las posibilidades del sonido, la imagen, el gesto y el movimiento como elementos de representación y utilizarlas para expresar ideas, sentimientos y vivencias de forma personal y autónoma en situaciones de comunicación y juego"

- "Conocer los medios de comunicación en los que operan la imagen y sonido, y los contextos en que se desarrollan, siendo capaz de apreciar artísticamente los elementos de interés expresivo y artístico". 
- "Expresarse y comunicarse produciendo mensajes diversos, utilizando para ello los códigos y formas básicas de los distintos lenguajes artísticos, así como sus técnicas específicas".

-"Realizar producciones artísticas de forma cooperativa que supongan papeles diferenciados y complementarios en la elaboración de un producto final".

En lo que respecta a los contenidos, en el área de Lengua se observan en los procedimientos de la subárea "Usos y formas de comunicación oral" expresiones referenciales y finalidades valorativas de la utilización de los textos orales: "Comprensión de textos orales atendiendo a las diferentes intenciones y a las características de la situación de comunicación"; "Interpretación de mensajes no explícitos en los textos orales (doble sentido, sentido humorístico, mensajes que denotan discriminación, hechos comprobables y opiniones, etc.)"; "Comentarios y juicio personal sobre los textos orales"; "Utilización de producciones orales como instrumento para recoger organizar la información, para planificar experiencias, para elaborar alternativas y anticipar soluciones para memorizar mensajes, etc.". Similares son los contenidos procedimentales de la subárea "Usos y formas de comunicación escrita": "Comprensión de textos escritos a partir del propio bagaje de experiencias, sentimientos y conocimientos pertinentes"; "Interpretación de mensajes no explícitos en los textos escritos...."; "Análisis, comentario y juicio personal sobre los textos escritos"; "Utilización de diversas fuentes de información escrita (biblioteca, folletos, prospectos, prensa, etc.) para satisfacer necesidades concretas de información". Por último, en la subárea de "Sistemas de comunicación verbal y no verbal" en el apartado de conceptos, desde un enfoque descriptivo, aparecen como contenidos: "Textos que utilizan de forma integrada sistemas de comunicación verbal y no verbal (en los medios de comunicación social, en la publicidad, etc.) y en lo referente a actitudes se observa un enfoque crítico hacia los mensajes de los medios de comunicación y de la publicidad: "Actitud crítica ante los mensajes que transmiten los medios de comunicación social y la publicidad, mostrando especial sensibilidad hacia los que suponen una discriminación social, sexual, racial, etc.".

En el área "Conocimiento del medio natural, social y cultural", desde un enfoque descriptivo, se recogen los siguientes conceptos: "Los sectores de producción. La publicidad y el consumo de los productos" y "Los medios de comunicación de la información; los medios de comunicación de masas: prensa, radio, televisión, cine, vídeo, satélites. Información: noticias y publicidad y el consumo; la información a través de la imagen; el ordenador. Los medios de comunicación interpersonales...". Es en el bloque de actitudes de esta área en el que se atiende a la enseñanza de los medios de comunicación desde una postura más crítica y desmitificadora: "Actitud crítica ante la promoción del consumo masivo de productos mediante la publicidad y ante la imagen que del hombre y de la mujer se ofrece"; "Actitud crítica ante las informaciones recibidas a través de los distintos medios de comunicación en la formación de opiniones con especial atención a la publicidad, a los estereotipos 
sexistas, racistas y al consumo". Así mismo, en los procedimientos de la subárea "Medios de comunicación y transporte" también se pretende que los alumnos sean receptores activos y críticos: "Iniciación en el análisis crítico de la información y de los mensajes publicitarios recibidos a través de los distintos medios"; "Análisis crítico de la utilización de la imagen del hombre y de la mujer en la publicidad".

También en el área de "Educación Artística" aparecen de manera explícita los medios de comunicación como contenidos conceptuales en la subárea de "La imagen y la forma": "Medios de representación más habituales: cinematografía, vídeo, televisión y ordenador"; en la de "La elaboración de composiciones plásticas e imágenes": "Las técnicas y los materiales de la elaboración plástica: fotografía, cine, televisión, vídeo, ordenador", "Manejo de instrumentos y aparatos (máquinas de fotografiar, vídeos, ordenador) para afianzar el rendimiento de los mismos" (contenido procedimental, enfoque tecnológico); en la de "Artes y cultura": "La obra artística de los medios de comunicación: Formas (según el soporte...) y tipos de mensaje". Teniendo en cuenta las actitudes críticas en los contenidos aparecen: "Valoración de las imágenes de modo crítico e interés por analizar los diferentes elementos contenidos en su composición".

Por lo que al apartado de criterios de evaluación se refiere también quedan definidas las exigencias de aprendizaje de la participación en diferentes situaciones comunicativas, la búsqueda de fuentes de información, la comprensión e interpretación de mensajes, o el comentario de manifestaciones artísticas, entre otros.

En el área de "Lengua castellana y literatura" se establecen los siguientes criterios de dicha índole:

- Participar de forma constructiva (escuchar, respetar las opiniones ajenas, llegar a acuerdos, aportar opiniones razonadas)...respetando las normas que hacen posible el intercambio en estas situaciones.

- Captar el sentido de textos orales de uso habitual mediante la comprensión de las ideas expresadas y de las relaciones que se establecen entre ellas y la interpretación de algunos elementos no explícitos presentes en los mismos...

- Manifestar preferencias en la selección de lecturas y expresar las propias opiniones y gustos personales sobre textos leídos.

- Localizar y utilizar diferentes recursos y fuentes de información de uso habitual en la actividad escolar (biblioteca, folletos, libros de consulta, medios de comunicación) para satisfacer necesidades concretas de información y aprendizaje.

- Producir textos empleando articuladamente la imagen y el lenguaje verbal (carteles, cómics...) y utilizando elementos sencillos de estos lenguajes (disposición 
en el espacio, contraste, color, tamaño...) para expresar intenciones concretas de comunicación.

- Identificar, en textos orales y escritos de uso habitual, planteamientos de determinados temas y usos de la lengua que suponen una discriminación social, racial, sexual, o de otro tipo, y tender a la autocorreción.

En el área de "Conocimiento del medio natural, social y cultural" se recogen los siguientes criterios relacionados con la recogida de información:

- Obtener información concreta y relevante sobre hechos o fenómenos previamente delimitados a partir de la consulta de documentos diversos (imágenes, planos, mapas, textos descriptivos...)

- Ordenar temporalmente algunos hechos históricos relevantes, y otros hechos referentes a la evolución de... los medios de comunicación a lo largo de la historia de la humanidad, utilizando para ello nociones básicas de sucesión, duración, simultaneidad...

- Abordar problemas sencillos, referidos al entorno inmediato recogiendo información de diversas fuentes (encuestas, cuestionarios, imágenes, documentos escritos) elaborando la información recogida (tablas, gráficos, resúmenes), sacando conclusiones y formulando posibles soluciones.

Y en el área de "Educación Artística (Musical y Plástica)" destaca la utilidad del empleo de los diferentes recursos expresivos en la producción de mensajes:

- Realizar individualmente o en grupo producciones artísticas sencillas donde se integran los diferentes lenguajes artísticos y expresivos (corporal, plástico, icónico y musical).

- Comentar de forma razonada alguna de las manifestaciones artísticas a las que el alumno y la alumna tienen acceso, relacionando los elementos presentes en la obra con la experiencia y gustos personales.

- Identificar algunas características plásticas y visuales observables (color, forma, textura, medida) en elementos naturales y en manifestaciones artísticas presentes en el entorno y establecer relaciones de semejanza y diferencia con las propias producciones.

- Describir alguno de los elementos constitutivos (signos, puntos de vista del observador, amplitud de plano, contenido, etc.) de un mensaje visual presente en el entorno.

- Utilizar los recursos expresivos del cuerpo, los objetos, la luz y el sonido para representar personajes y situaciones dramáticas sencillas y para comunicar ideas, sentimientos y vivencias. 
Con estos objetivos, contenidos y criterios de evaluación, la Educación Primaria contribuye al desarrollo capacidades como la comunicación, el pensamiento lógico y el conocimiento del entorno social y natural, todos ellos relacionados, directa o indirectamente, con el aprendizaje de las pautas de observación, interpretación y análisis de las producciones mediáticas.

\section{Trabajo de campo: análisis del consumo televisivo infantil por parte de los padres y profesores}

Para comprobar la importancia que padres y profesores ofrecen al medio televisivo, llevamos a cabo un análisis de carácter experimental para observar tendencias, aunque no se tratara de una muestra representativa, realizando un cuestionario a un grupo de 48 padres y 20 profesores de diferentes centros de la Comunidad de Madrid. Los objetivos concretos de este análisis fueron:

- Determinar la importancia que los padres dan al uso que hacen sus hijos de la TV, materializado en si conocen sus preferencias.

- Analizar la importancia que tienen los medios de comunicación en el sistema educativo (DCB de Enseñanza Infantil y Primer Ciclo de Enseñanza Primaria).

- Concretar qué agentes sociales deberían formar a los niños en su uso televisivo (familia, escuela,...).

\subsection{Análisis de los cuestionarios de los padres}

Es destacable que a la pregunta acerca de qué tipo de contenidos desearía que se emitieran para el público infantil hay clara unanimidad en que lo deseable serían "programas educativos y entretenidos de calidad". El calificativo "entretenidos" predomina considerablemente en las respuestas de los padres en los casos que trabajan fuera del hogar ambos miembros de la pareja, ya que arguyen no disponer de demasiado tiempo para jugar y ver la televisión con sus hijos, por lo que podría afirmarse que buscan una "niñera electrónica" en la pantalla.

Los contenidos son lo que más preocupa a la mayoría de los padres, y dicen ver más aspectos negativos que positivos en la actual programación televisiva. Si bien el $100 \%$ afirman interesarse por lo que su hijo pueda ver en televisión, existe un $20 \%$ de los encuestados que reconoce abiertamente no comentar ni explicar a sus hijos nada de lo que ven. En la mayoría de los casos alegan no sentirse preparados ante los cambios tecnológicos de los medios, asimismo tampoco conocen bien los formatos y contenidos, con lo cual no se creen capacitados para transmitir una buena información y educación a sus hijos.

A la pregunta sobre “¿Quienes deberían educar para los medios a los niños?", la amplia mayoría responde (75\%), que es tarea de los padres en primer lugar, en tanto que el $20 \%$ restante opina que es una labor conjunta de padres y educadores, 
y es una pequeña muestra (5\%), quienes opinan que además de la familia y la escuela, hay que sumar también a los propios medios como agentes socializadores $y$ formadores en este sentido.

A continuación, incluimos otras respuestas ofrecidas por los padres en los cuestionarios sobre los siguientes aspectos (Marta Lazo y De Ángel García, 1997: 332-333):

- Quién decide lo que ve su hijo/a en televisión:

Aproximadamente la mitad dejan la elección al niño y la otra mitad son los padres los que deciden, casi siempre en los niños de más temprana edad "porque hay ciertos programas que no les interesa ver porque son muy pequeños" (madre de una niña de 4 años).

- Por qué le gusta que su hijo/a vea la televisión:

La mayoría responden que para "entretenerse", en segundo lugar para "aprender". En menor medida, apuntan que para "informarse" y para "desarrollar su creatividad"

- Aspectos positivos que le ofrece la TV al niño:

Los más nombrados son: "entretiene, divierte", "informa" y "enseña, educa, instruye". Otras utilidades que los padres le dan en positivo son: "acompaña", "relaja" y "da pie al diálogo". También los hay que aprecian "muy pocos".

- Aspectos negativos que le ofrece la TV al niño:

Destacan en un alto porcentaje "los contenidos violentos y agresivos", le siguen: "la manipulación política/propaganda", "subjetividad informativa", "el consumismo/anuncios", "cambios horarios continuos/poca puntualidad", la falta de calidad en la programación "programas basura", "falta de programación infantil", "escandaliza/pornográfica", "monótona/aburrida", "crea falta de comunicación familiar", "comedura de coco" y "crea dependencia".

- Se asemejan los diferentes aspectos que ofrece la televisión a los de su vida cotidiana:

Se aprecia que la clase media alta contesta en mayor medida que no, mientras que en las otras dos clases sociales se considera en un 50\% ("las series españolas son muy realistas", es una de las respuestas).

- Credibilidad de las informaciones y los contenidos que ofrece la televisión:

Impera la opinión de que sí son creíbles. Algunas opiniones: "Existe la posibilidad de contrastarla porque hay varios canales"; por otro lado, también se aprecian 
respuestas acerca de los intereses que la mediatizan: "Creo que es una batalla por ganar audiencia".

- Cómo le gustaría que fueran los programas de televisión:

La mayoría señalan que "educativos y entretenidos", respuestas que suelen aparecer unidas. También se mencionan: "creativos", "variados", "buenos", "animados", "menos crueles" y "que desarrollen a la persona.

- Qué temas considera que deberían de tratarse más:

Entre las respuestas más repetidas destacan los temas relacionados con "la ecología/medio ambiente", "salud", "humanidad", "educativos", "divulgativos" y "culturales". Otros que se mencionan aisladamente: "la realidad del país", "religión", "respeto a los demás", "cine", "política" y "éticos".

- Qué temas considera que deberían tratarse menos:

En algunos casos, se confunden los temas con los géneros televisivos, así se incluyen "los reality shows" o "los concursos". Los primeros son los que menos gustan porque, como señalan, "juegan con los sentimientos y la vida de la gente". También "los anuncios" son incluidos como "temas" que deberían tener menor duración.

Algunos temas que se indican: "la vida de los famosos", "los cotilleos", "los bélicos" y "la mortalidad infantil".

- Opinión sobre la televisión actual:

Una vez que se les ofrece la posibilidad de opinar críticamente, son más los aspectos negativos que se señalan que los favorables. Predominan las citas de que es "demasiado reiterativa la programación entre canales", "existen muchos programas de relleno", "es muy competitiva", "es de mala calidad" y también se adjetiva como "deprimente, comunicativa y fehaciente".

- Qué debería cambiar:

Se vuelven a repetir muchas de las contestaciones anteriores: "que la programación fuera más variada y más creativa", "el efecto copia", "menos publicidad", "menos contenidos violentos", "las novelas de hace veinte años", ...

En cuanto a los contenidos también se demanda: "menos política", "menos sexo", "menos programas de parejas y de las problemas de las personas". Hay quien es muy crítico: "el 90\%"; y muy conformista "nada porque no depende de mí". 
Como se observa en los párrafos anteriores no se proponen alternativas tan sólo se sugiere reducir lo que no gusta, sólo uno de los encuestados incrementaría "la programación infantil" pero tampoco plantea con qué formatos y contenidos.

- ¿Podría definir que es la "plataforma digital"?

Aproximadamente la mitad sí que lo conocen y definen, pero son bastantes los que se sienten desinformados.

- ¿Se siente preparado e informado ante los cambios tecnológicos?

La amplia mayoría, un $75 \%$, afirman que no se sienten preparados, aunque en varias ocasiones indican que lo intentan.

- ¿En el seno de la sociedad quien elige los programas de TV?

Son más los que contestan que "la sociedad a través de encuestas", le sigue el grupo de los que opinan "los grupos de poder económico", "los directivos en las cadenas privadas y el Gobierno en la pública". También hay quien responde que "la sociedad no, por mucho que se miren las audiencias".

- ¿Le interesa y/o preocupa lo que su hijo/a pueda ver a través de la televisión?

Casi el 100\% señala que "Si": "porque influye en su educación y desarrollo y porque hay programas agresivos que no debería ver", "porque hay programas que son para adultos y se emiten en horarios para niños". Algún padre opina que "la familia y el ambiente familiar influye bastante más".

- Cómo le gustaría que fueran los programas que ve su hijo:

La mayoría demanda programas "culturales y educativos", respuesta que va unida a que tengan formatos "entretenidos". También apuntan que "más cortos, claros, comprensibles e informativos y menos violentos".

- Explica o comenta con su hijo/a los contenidos de la televisión:

Casi un $80 \%$ inciden en que "sí", "porque lo que ofrece la televisión no es lo mismo que la realidad", es una de las respuestas.

- Quién debe preparar y educar a su hijo para ver TV:

La contestación más generalizada es que son ellos quienes tienen esa función, en segundo lugar opinan que ellos junto con la escuela. En un mínimo porcentaje, también se incluye a los medios de comunicación entre los preparadores.

- ¿Le interesa que se hagan estudios acerca de la influencia de la TV y los medios de comunicación? 
Más de un $80 \%$ se muestran interesados. Vamos a recoger algunas de las respuestas porque no sirven para ver la utilidad que los padres dan a este tipo de estudios:

- "porque, al final, valen para que mejoren los programas de televisión".

- "porque conociendo los aspectos negativos podemos adoptar soluciones".

- "porque, entre todos, podemos ir cambiando".

- "porque son de interés público".

- "porque los niños pueden tener mala influencia y mediante los estudios puede ser evitada".

\subsection{Análisis de los resultados de los profesores}

Con el fin de establecer y concretar la diferente importancia que están cobrando los medios de comunicación y las nuevas tecnologías en cada Centro Escolar y dentro de ellos en los ciclos y niveles educativos que hemos analizado, hemos querido saber la opinión de los profesores.

Como punto de partida, nos planteamos que el Proyecto Educativo de Centro, PEC, es muy genérico y que sólo a través de la visión singular de los profesores que han participado en esta investigación y con los que hemos experimentado el acceso que tienen a la enseñanza de los medios, se podría llegar a establecer como aplican empíricamente el DCB a su Programación de Aula. La influencia que los profesores ejercen en sus alumnos es realmente importante, así "la forma en que se utilicen los medios de comunicación audiovisual en el aula servirá, bien para reforzar la hipnosis colectiva que se genera fuera de la escuela, bien para facilitar el aprendizaje o bien para instrumentalizar mecanismos que ayuden a defenderse del poder de los medios de comunicación" (Aparici y García Matilla, 1987). Las realidades, visiones, opiniones y perspectivas de cada profesor han sido muy diversas.

¿Cómo llega el niño a contactar con el uso perceptivo y crítico de los medios de comunicación?, ¿Dónde, en el colegio o en su casa?, ¿Quién le introduce en su enseñanza, sus padres, sus profesores,...? , estas y otras cuestiones han sido las que hemos tratado de responder.

A continuación, introducimos las respuestas que han ofrecido los profesores a los cuestionarios:

- ¿Cómo se aplica el Diseño Curricular Base, D.C.B., en su Programación de Aula?

La mayoría de los enseñantes se ciñen a los niveles de concreción que establece el Ministerio de Educación y Ciencia. Una muestra de ello es la respuesta de uno de los profesores de Educación Infantil: "Nuestra programación de aula (P.A.) es el 
resultado de las distintas concreciones del D.C.B. Una primera concreción es el P.C.C. (Proyecto Curricular de Centro), y en el siguiente paso la P.A., teniendo en cuenta las distintas adecuaciones al medio que se hacen en el P.E.C. (Proyecto Educativo de Centro)". Desde una perspectiva constructivista, otros profesores afirman aplicarlo adaptándolo a las circunstancias y condiciones de la clase: "Se tiene en cuenta la diversidad de alumnos, los temas transversales, los recursos disponibles en el Centro o fuera de él, etc.".

- ¿Cómo se integra la enseñanza de los medios de comunicación en su clase, como recurso didáctico, como bloque temático o como materia transversal?

El $50 \%$ responde que utiliza los medios de comunicación simplemente como recurso didáctico, el otro $50 \%$ afirma emplearlos como bloque temático y un $35 \%$, además de aplicarlo como recurso o como bloque temático, lo integra como materia transversal: "De las tres maneras, usamos medios como recurso, como bloque: "Los medios de comunicación" y como transversal, en todos los temas buscamos información en ellos: prensa, televisión, vídeo", indica una profesora de Enseñanza Infantil.

- ¿Enseñanza de medios de comunicación o con medios de comunicación?

El $75 \%$ opinan que ambas variables son importantes y se complementan, mientras que el $25 \%$ restante responde que únicamente atienden a la "enseñanza con medios" por considerar que los niveles de educación son iniciales y los niños en estos estadios aún no están preparados para la "enseñanza de los medios", en este sentido uno de los profesores responde que "Enseñanza de y con. Quizá enfatizamos más en él por tratarse de un ciclo en el que el aprendizaje es eminentemente experimental y sensorial".

- ¿Qué opina de la aplicación en la enseñanza de las Tecnologías de la Información?

Todos los profesores están de acuerdo con la importancia que las tecnologías tienen en la sociedad actual por lo que la educación no puede dejarlas al margen, pero en ocasiones su aplicación es supeditada a los recursos económicos con los que cuentan. Por otra parte, algunos pese a estar conformes con su aplicación piensan que no se debe de conceder más relevancia que la que tienen: "Es un recurso más, pero sin mitificarlo, sin poner especial acento y sin olvidarnos de otras tecnologías base de gran utilidad y disponibilidad en la escuela".

- ¿Cree que los niños están preparados y protegidos ante la amplia oferta de televisión?

En su totalidad responden negativamente, algunos incluso afirman que los adultos tampoco están suficientemente preparados. Así uno de los profesores señala que tampoco lo están la mayoría de los que han de enseñar y educar a los niños a ser 
comedidos en la utilización de la televisión. Asimismo, indica: "Es muy fácil y sencillo que la televisión sea la chacha eléctrica que entretiene, aunque a la vez perjudica y destruye juegos e imaginación".

- ¿Cree que los padres protegen a los niños de los contenidos televisivos que no son aptos para ellos?

"Creo que están muy desorientados. No todos los programas infantiles son aptos para niños. Impera la dictadura de la audiencia y del anunciante y los padres están sometidos a ella, y a la propia demanda de sus hijos (por contagio social en el cole, calle, etc.). Los padres están preocupados por la tele que ven sus hijos pero no dan alternativa, al final lo fácil es enchufar al niño a la televisión: Teleniños".

"En muchos casos no, pero no es sólo de ellos la culpa. Actualmente, falta dar una dimensión de información pedagógica y de programación formativa para los niños/niñas desde los propios medios televisivos".

Bajo los conceptos expuestos en estas dos opiniones se engloban la mayoría de las respuestas dadas a esta cuestión.

- En su opinión, ¿quién debe protegerlos?

Se destaca, en primer lugar, la responsabilidad que tienen los padres en todos los ámbitos de la educación de sus hijos, también, en la preparación como receptores de los medios audiovisuales estarían implicados los Centros de Enseñanza, así como los propios medios de comunicación y organismos oficiales competentes.

Estas son algunas de las respuestas más significativas:

- "Es muy difícil decir quien, porque los padres son los máximos responsables de la educación de sus hijos. ¿Quizá el Estado?, ¿quizá alguna asociación protectora de la infancia?, no sé. Lo cierto es que mientras la televisión no cambie sus programas por propia iniciativa, los televidentes seguirán viendo los programas. La televisión se basa en que tiene derecho a poner lo que quiera y la gente a ver lo quiera. Creo que tiene que partir la idea del propio ente televisivo".

- "En mi opinión, el primero en proteger sería el propio ente televisivo, quien formando a especialistas pudieran asesorar e informar en los colegios, A.P.A.S y Escuelas de Familia, así como en programas televisivos específicos para ello, ya que, como se suele decir 'una imagen vale más que mil palabras".

\section{Conclusiones}

La enseñanza de los medios es fundamental en las edades preescolares puesto que en esta etapa vivencial es cuando los niños comienzan a asentar sus patrones de 
conducta, unos antes que otros debido al estadio evolutivo, pero es entorno a los cinco años cuando empiezan a tomar conciencia de la realidad circundante. Los padres y educadores son conscientes de la importancia que tienen las nuevas tecnologías en la vida individual y social de los educandos y creen necesaria una buena educación con y de los medios desde las primeras etapas educativas.

Los profesores piensan que los niños no están protegidos educativamente respecto a los contenidos que ven en televisión y que la mayoría de los adultos tampoco están preparados para mostrarles ese aprendizaje. Generalmente, plantean que deben ser los padres los encargados de afrontar esta función. En algunos casos, indican que debe ser el propio medio televisivo el que emita contenidos formativos a tal efecto y el que se ocupe de asesorar pedagógicamente a especialistas que pudieran informar en los colegios. Los padres muestran interés pero no se sienten preparados para afrontar este reto educativo y socializador de sus hijos y opinan que la escuela debe servirles como complemento de las orientaciones que ofrecen a sus hijos.

Las cadenas de televisión, además de no ofrecer espacios con finalidad pedagógica que contribuyan a formar en cómo ver el medio con mirada analítica, cuentan con programaciones para el público infantil que no responden a las exigencias mínimas de calidad que se contemplan en la legislación española y europea, ni posibilitan opciones interactivas para conocer la opinión de los niños.

Hay que potenciar una comunicación más horizontal que vertical centrada en el receptor, donde se le de más protagonismo al niño, quien a pesar de no tener derecho al voto, sí tiene voz y se le ofrezca la posibilidad de acceder a los medios de comunicación, a través de medios interactivos y participativos, que son preferibles a los unidireccionales existentes en la actualidad.

\section{Bibliografía básica}

AA.VV. (Dirección Ricardo Berea): Análisis de la demanda de servicios para la primera infancia. Ed. Ministerio de Asuntos Sociales. Madrid, 1992.

AA.VV. (Dirección Sergio Sánchez Cerezo): Enciclopedia de la Educación Infantil. Recursos para el desarrollo del currículum. Ed. Santillana Infantil. Madrid, 1993.

AA.VV. (Coordinación Pilar Burgués Zaera): Diseño Curricular Educación Infantil. Ed. Direcció General d’Ordenació y Innovació Educativa de la Conselleria de Cultura, Educació y Ciència. Valencia, 1990.

AA.VV. (Coordinación Pilar Pérez Esteve): Diseño Curricular Educación Primaria. Ed. Direcció General d'Ordenació y Innovació Educativa de la Conselleria de Cultura, Educació y Ciència. Valencia, 1990. 
AA.VV.: Proyecto Curricular de Educación Primaria. Vicens Vives. Barcelona, 1991. AA.VV.: Televisión, currículum y familia. MEC. Madrid, 1994.

APARICI, R. y GARCÍA MATILLA, A.: Imagen, vídeo y educación. Ed. Fondo de Cultura Económica, Paideia. Madrid, 1987.

CAMPUZANO RUIZ, A.: Tecnologías audiovisuales y educación. Akal. Madrid, 1992.

EINES, J. y MANTOVANI, A.: Teoría del juego dramático. Ed. Instituto Nacional de Comunicación de la Educación. Madrid, 1980.

FUENZALIDA, V. y HERMOSILLA, Mํㅡㄹ E.: El televidente activo (Manual para la recepción activa de televisión). Ed. Corporación de Promoción Universitaria. Santiago de Chile, 1991.

MANTOVANI, A.: El teatro: un juego más. Ed. Nuestra Cultura, Serie Pedagogía-De cero a seis. Madrid 1980.

MARTA LAZO, C. y DE ÁNGEL GARCíA, N.: Niños y televisión: de los estudios sobre los efectos a los de recepción activa. Revista de Ciencias de la Información, 1997.

MARTA LAZO, C. y DE ÁNGEL GARCíA, N.: Análisis empírico sobre la decodificación del mensaje televisivo, según el proceso evolutivo en niños de clase media de 4 a 7 años. Actas del I Congreso Internacional de Formación y Medios. Universidad de Valladolid. Segovia, pp. 327-333, 1997.

MARTÍN SERRANO, M.: La participación de los medios audiovisuales en la construcción de la visión del mundo de los niños. Infancia y Sociedad, núm. 3. Madrid, 1990.

PIAGET, J.: El nacimiento de la inteligencia en el niño. Aguilar. Madrid, 1969.

VEGA ALONSO; R.: Psicología paidológica y pedagógica. Ed. Instituto San Isidoro de Sevilla. Sevilla, 1958.

WOLF, M.: La investigación de la comunicación de masas. Crítica y perspectivas. Paidós. Barcelona, 1987.

YOUNIS, J.A.: El niño y la cultura audio-visual. Coedic. Ayto. de Santa Lucía de Tirajana, Ayuntamiento de Agüimes y Centro de la Cultura Popular Canaria. Santa Cruz de Tenerife, 1988. 